\title{
Jesús Arias y el universo Morente
}

\author{
Irene del Carmen Chicharro Martínez \\ Graduada en Historia y Ciencias de la Música \\ Máster en Patrimonio Musical
}

El presente artículo aborda a grandes rasgos la participación de Jesús Arias Solana (1963-2015) en el proyecto Omega de Enrique Morente. Músico, poeta y periodista, Arias es una de las personalidades clave en el panorama cultural de Granada de las últimas décadas, ya que, entre otras aportaciones, fue uno de los precursores del género musical punk en dicha ciudad y parte esencial para conocer la crítica musical en la prensa granadina de esos años. Jesús Arias, Lagartija Nick y Enrique Morente lograron con el proyecto Omega un espacio de interdisciplinariedad y heterodoxia dentro del mundo del rock y el flamenco.

Palabras clave: Jesús Arias; Enrique Morente; Omega; interdisciplinariedad en el arte.

This article broadly addresses the participation of Jesús Arias Solana (1963-2015) in Enrique Morente's Omega project. Musician, poet and journalist, Arias is one of the personalities key in the cultural panorama of Granada in recent decades, since, among other contributions, was one of the precursors of the punk musical genre in that city and an essential part to learn about the music criticism in the Granada press of those years. Jesús Arias, Lagartija Nick and Enrique Morente with the Omega project they achieved a space of interdisciplinarity and heterodoxy within the world of rock and flamenco.

\section{Introducción}

Cuando dos astros se alinean, puede producirse una conjunción astronómica. En este caso, más que provocarse dicha conjunción, se originó el meteorito Omega. Tal y como advertía Jesús Arias sobre Enrique Morente en una entrevista titulada Músiques clandestines-5 de maig (Sáenz, 2012, minuto 35'30"- 36'35"):

Enrique era un tío genial, un cachondo mental. La primera vez que escuchó a Lagartija Nick dijo "yo ya no quiero ser cantaor flamenco, yo quiero ser cantante de rock, yo quiero ser vuestro cantante". Era un tío absolutamente cercano, lleno de sabiduría. Recuerdo cuando a la una de la mañana sonaba el interfono de mi casa, y yo preguntaba: “Quién es?", y él decía: "Soy Enrique", y subía con una botella de JB y decía: "Saca el ajedrez que vamos a tener ideas", y ahí estábamos hasta las cinco de la mañana, a ver a quién se le ocurría la idea más loca. Entonces, una vez estábamos ya borrachos y con ideas disparatadas, decía: "Jesús, apunta eso". En esas conversaciones yo recuerdo que le dije a Enrique una noche: "Enrique, se me ha ocurrido hacer una seguiriya con alarmas industriales", y dice: "Jesús, mira, yo ya estoy con una banda de rock, con una banda punki, con batería, con guitarras eléctricas, no me hagas esto que ya me meten en la cárcel”. Era un tío muy divertido.

La relación entre Enrique Morente y Jesús Arias no sólo se caracteriza por la amistad en sí, sino que además, conectan en la manera en la que interpretan el concepto de arte. Ambos entienden por arte un ente abierto, un espacio donde la interrelación con otras disciplinas y la escucha de todo tipo de sonidos tienen cabida y que, además, si se resuelven de forma correcta, pueden confluir a la perfección durante el desarrollo de la obra. Por esta misma razón nace Omega.

Revista de Investigación sobre Flamenco "La madrugá" 
(C) Servicio de Publicaciones de la Universidad de Murcia

http://revistas.um.es/flamenco

Para conocer el papel de Jesús Arias en el proyecto, previamente debemos situar y contextualizar brevemente la biografía de este polifacético artista (figura 1).

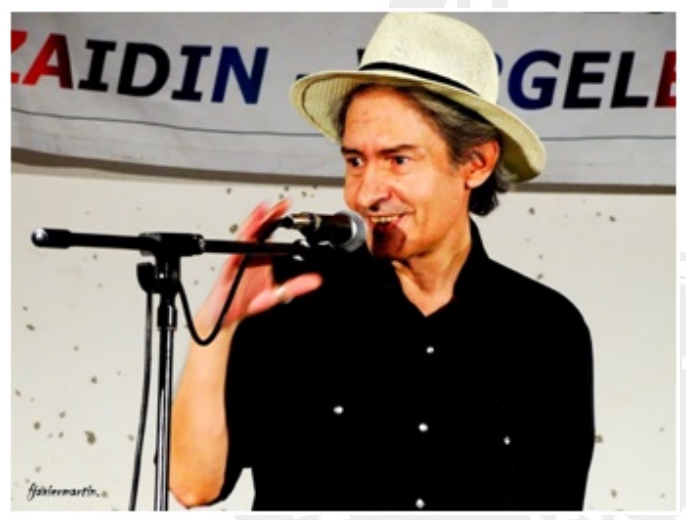

Figura 1. Jesús Arias en la entrega del "Gorrión de Plata 2014" por la Asociación de Vecinos del Zaidín (foto de Martín Ruiz, recuperada de https://cutt.ly/3TK1QxQ)

Jesús Arias Solana (1963-2015), poeta, músico y periodista granadino es una figura fundamental para entender el panorama cultural granadino de las últimas décadas. Creció rodeado de un ambiente con inquietudes culturales y artísticas. El propio artista comentó sobre sus padres, Antonio Arias y Carmen Solana:

Tanto mi padre como mi madre me inculcaron el respeto por la cultura, por la música, las artes, la curiosidad, la honestidad y la necesidad de cambiar las cosas socialmente si veías que eran injustas. Creo que mis padres eran punkis sin saberlo (Iglesias Castro, 2015).

De este matrimonio nacieron otros dos hijos, Antonio (líder de Lagartija Nick) y José Ángel, siendo Jesús el mayor de los tres (figura 2).

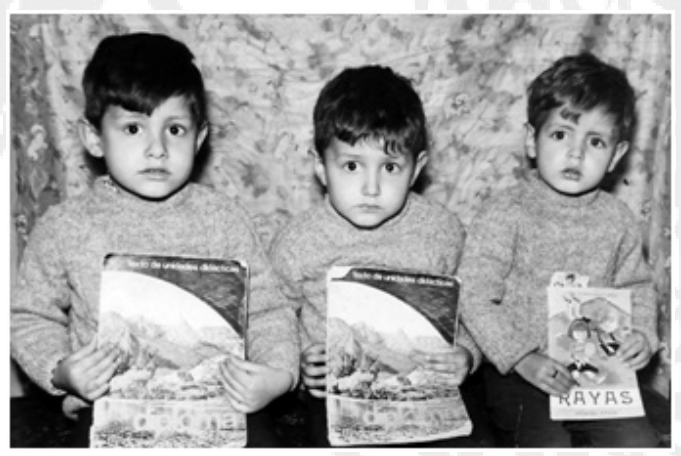

Figura 2. De izquierda a derecha, Jesús, José Ángel y Antonio Arias Solana (recuperada de https://cutt.ly/kTK1AgR)

La infancia de Arias transcurrió en el entorno familiar, condicionado por la situación de represión social y política del momento. Una de las razones por las que el mundo cultural llamó su atención desde pequeño es porque encontró en él un canal ideal para comunicarse. 
Desde muy pequeño, una de las inquietudes artísticas por las que mostró especial interés y que marcaría su vida, fue la musical. Tal era la pasión de Jesús por la música que, en 1970, con tan sólo siete años, les decía a sus hermanos como anticipando su futuro: «Cuando seamos mayores vamos a ser artistas» (Pereira, 2017). Desde ese momento hasta que cumple dieciocho años, está permanentemente en contacto con la música. Al mismo tiempo, Jesús Arias desarrollaría el gusto por la palabra, más concretamente por la poesía y por la literatura. Gracias al gusto poético de sus padres, empieza a tener contacto con los escritos de diferentes poetas, entre los que destaca Federico García Lorca (cuestión que le acercaría años después a Enrique Morente). Su interés por el sentido y significado de las palabras, por la construcción de frases o por las metáforas, entre otras cuestiones, hacen de él un lector voraz. Gracias a ello, la capacidad de Jesús Arias para interrelacionar música y palabra se potenciaría a partir de este momento.

\section{Aproximación a las distintas facetas culturales de Jesús Arias}

\section{2.1 Faceta musical}

Su concepción de la música fue evolucionando en función del momento y la circunstancia en la que se encontraba. Todavía era adolescente, ya empezó a interesarse por grupos de habla inglesa y por la música que se estaba produciendo en Granada (entre ellas, el flamenco).

En 1981, con dieciocho años, entró a formar parte de T.N.T. (figura 3), grupo capitaneado por Ángel Doblas y José Antonio García. Con esta banda forjó gran parte de su carrera musical, gracias a temas como "Cucarachas", "1984 (Euroshima)" o "Sin Futuro" (Musikaze, 2010) algunas de ellas compuestas por Arias con anterioridad.

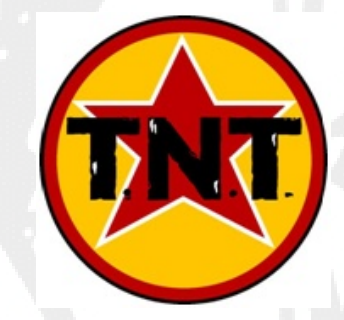

Figura 3. Uno de los logotipos de TNT (recuperado de https://cutt.ly/lTK9jT7)

Una de las fechas más importantes para la formación será el invierno que transcurre entre 1981 y 1982. En el local de ensayo de unos amigos de Albolote (Granada), el grupo decide grabar su primera maqueta, Una Naranja Mecánica, que englobaba dieciséis temas. Posteriormente la cinta fue enviada a Radio 3, al programa "Diario Pop"1 presentado y conducido por Jesús Ordová:2 En ese momento T.N.T. estaban siendo escuchados a nivel nacional, llegando a posicionarse en el número 1.

El grupo compondría muchos más temas, pero sin duda, otro de los trabajos a destacar es Rimado de Ciudad, pues supondrá un antes y un después en la concepción de proyecto interrelacionado (idea que le servirá posteriormente para Omega).

\footnotetext{
${ }^{1}$ Diario Pop (1982-2007) programa de radio en Radio Nacional de España que recepcionaba nuevas propuestas musicales (maquetas y discos) del panorama musical nacional.

${ }^{2}$ Jesús Ordovás (1947) es un periodista, escritor y locutor de radio español, considerado uno de los principales impulsores de la "Movida Madrileña", a su vez codirector junto a José M. Rey y Tomas Fdo. Flores de "Diario Pop".
} 
(C) Servicio de Publicaciones de la Universidad de Murcia

http://revistas.um.es/flamenco

A pesar de estar fraguándose desde finales de 1982, fue en la primavera de 1983 cuando el álbum vio la luz. Se trataba de un proyecto totalmente novedoso en la ciudad de Granada. A caballo entre Madrid y la capital nazarí, Jesús Arias mantenía relaciones con personas del mundo cultural de una y otra ciudad. En Granada, gracias a encuentros en bares o pubs como La Tertulia (a partir de 1981) o Planta Baja (desde abril de 1983), trató con personalidades de diversas disciplinas, de la propia Granada y de otras procedencias. A través de Mariano Maresca, Jesús Arias conoció en ese momento a Javier Egea, Antonio Muñoz Molina, Juan Vida, Álvaro Salvador y Luis García Montero, entre otros (Molina, 2015). El propio Mariano Maresca, Catedrático de Filosofía del Derecho, fue el precursor de este proyecto. Así lo reconoció Jesús Arias: lo mencionó de la siguiente manera «él nos metió el "gusanillo" de hacer el "loco"con Rimado de Ciudad, él fue el que nos convenció de que le pusiéramos música a Luis García Montero» (Tébar, 2010, minuto 12 '20"- 13 '25").

La idea para este trabajo era la creación de una idea común entre poesía, música y fotografía a través de una visión realista de Granada, con sus claros y sin obviar sus oscuros. Conociendo la interrelación de artistas de todas las especialidades, no ha de sorprender que surgiese un trabajo como este. Sería la primera vez que un grupo de música punk y otro heavy se encargara de poner música a poemas. La poesía era la de un joven Luis García Montero con sus Coplas a la muerte de un colega, en homenaje a Jorge Manrique (Molina, 2015). Con Mariano Maresca en la dirección, Luis García Montero como poeta, las fotografías de José Garrido y Javier Algarra y el diseño de Juan Vida, la música desempeña un papel estelar.

En efecto, Maresca convoca a T.N.T. y a Magic para que se encargaran de la música. Ambos grupos se dividieron la tarea, que dio como resultado dos temas: el número uno sería para T.N.T., interpretando "Coplas a la muerte de un colega" (casi once minutos de duración); el número dos, para Magic con "El Aguilucho" (mismo tiempo). La música de "Coplas a la muerte de un colega" estaba pensada en un principio para una formación orquestal, pero una vez que se supo el presupuesto, se redujo a los instrumentos de ambas bandas. La idea de Jesús Arias para este proyecto era que una banda punk, en este caso T.N.T., tocara instrumentos como timbales o violoncelos y, de esta manera conseguir algo que nunca antes se había hecho en Granada, ver a un grupo punk tocando instrumentos "clásicos" (Tébar, 2010). Aunque esto no se llegó a realizar como tal, sí que estaban haciendo algo que no se había hecho antes, juntar en el mismo proyecto la poesía inspirada en el Siglo de Oro y la música de aquel momento, precedente del que se sirvió Arias para proyectos posteriores. Aunque la banda siguió en activo y componiendo más temas, tras sus idas y venidas, el grupo se separó de manera definitiva en 2010.

Es en 1984, cuando Arias (quien estaba en plena ebullición tras el éxito de T.N.T.), conoce a uno de sus referentes, el líder de The Clash, Joe Strummer, quien vino a Granada en busca de refugio huyendo de la fama obtenida en Reino Unido y Estados Unidos (figura 4).

$\mathrm{Al}$ principio Jesús Arias ejerció como profesor y traductor de Strummer (Molina, 2015) para, posteriormente, hacerse amigos y confidentes, y así siguieron hasta el fallecimiento de Strummer. Una de las inquietudes que ambos compartían era su pasión por Lorca. Comenta el propio Arias:

Creo que había asistido a una representación de la obra Yerma en Londres y al día siguiente decidió buscar los restos de García Lorca en Granada. Eso fue lo que él me dijo: «He venido a buscar los restos de García Lorca en Granada». Joe había llegado a Granada con una pequeña Antología poética de Lorca en versión bilingüe que, desde muchos años antes, la conservaba. El día en que me enseñó el libro, vi el poema "Despedida": «Si muero/ dejad el balcón abierto/ el niño come naranjas / desde mi balcón lo veo (...)». Ese poema, en inglés, se llama "Farewel" y, curiosamente, en la cultura inglesa, que es algo que me sorprendió mucho, no llama la atención Poeta en Nueva York, que para un hispano-hablante es un derroche de imágenes... Lo que a los británicos e irlandeses cautiva de Lorca, traducido al 
Revista de Investigación sobre Flamenco "La madrugá" n. ${ }^{\circ}$ 18, diciembre 2021, ISSN 1989-6042

inglés, es Poema del Cante Jondo y Romancero Gitano (cit. por Iglesias Castro, 2015).

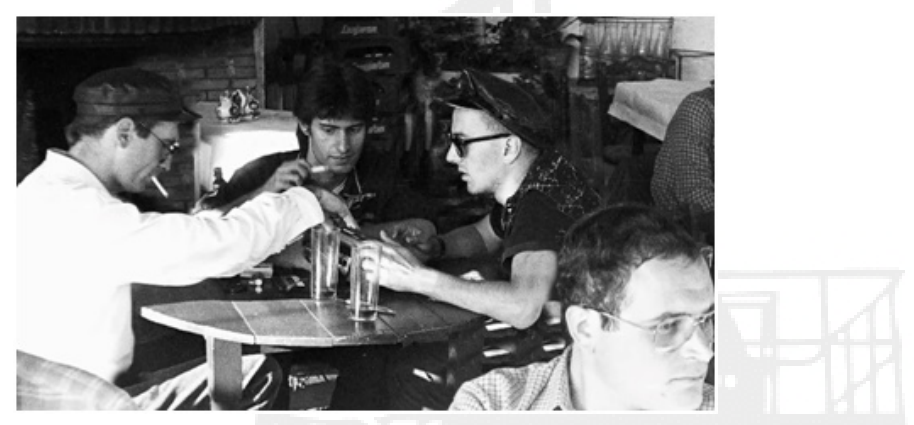

Figura 4. Jesús Arias y Joe Strummer en el Silbar (archivo personal de Jesús Arias; recuperada de https://cutt.ly/rTK4ELq.)

La pasión de Arias por Lorca, inculcada por sus padres, unida al interés que despertó en él la poesía tras Rimado de Ciudad, hizo que ambos encontrasen en el poeta granadino un punto en común importante. Tal es así, que Arias narró la siguiente anécdota sobre Joe Strummer:

Me recogió en un coche enorme que había comprado gracias al dinero que le prestó Santiago Auserón y fuimos hasta Víznar. Allí quiso que compráramos palas para desenterrar el cuerpo de Federico García Lorca, pero le quise hacer ver primero el lugar para que se diera cuenta de que aquello era imposible. Una vez allí y después de la profunda emoción que sintió al verlo me hizo prometer que escribiríamos una canción juntos y que algún día iríamos allí todos los amigos y tocaríamos (cit. por Iglesias Castro, 2015).

A Arias se le quedó grabada una de las frases que Strummer le susurró cerca del lugar donde está enterrado Lorca: «Aún puedo escuchar el grito de los muertos» (ibidem).

En cuanto a la promesa de componer la canción "Lorca", años después Jesús Arias la cumplió. En su archivo personal hemos encontrado parte de la letra de esta canción que dedica a Strummer (que falleció y no pudo cumplir su promesa) y a Lorca, llamada "Strummer/Lorca".

Aparte de T.N.T., en los últimos años de vida aparece Qüasar, banda con la que produce el disco Eclipse parcial de lunas, una recopilación de doce temas que resumen el proyecto Eclipse (cuarenta canciones), en creación desde 1992.

Por último, también debemos hacer hincapié en su labor compositiva de obras colosales, como por ejemplo Mater Lux o la obra inconclusa Los cielos cabizbajos. La primera, Mater Lux, es una cantata que, en principio, dedicó a la Virgen, aunque después fue su madre, Carmen Solana, la dedicataria de la misma (Rodríguez, 2015). Dividida en un principio en catorce partes -inspiradas en las madres que tenían felicidad plena por el hecho de ser madres y en las que tenían dolor por diferentes circunstancias, «las madres crecientes y las madres menguantes» (Rodríguez, 2015) - finalmente se quedó en nueve; en este orden: "Ecce Lux", "Fuga y cantiga/nana", "Embryo", "Dioses en la oscuridad", "Aynadamar", "Umbra aeterna", "Mare serenitatis", "Sit tibi terra levis" y "Grand finale" (Coro Canticum Novum, 2014). En la obra se incorporaban sonidos pregrabados, un theremin, un yunque, la voz flamenca de una cantaora (Soleá Morente fue la elegida) y contó también con la colaboración especial del cantaor Juan Pinilla. Al mismo tiempo, se une el canto de un coro -Canticum Novum- y un órgano, a cargo de Ricardo Rodríguez, como abrigo instrumental. Además de estos intérpretes, participaron también Eric Jiménez, a la percusión, Víctor Parejo en la producción y, como director, Jorge Rodríguez Morata. 
(C) Servicio de Publicaciones de la Universidad de Murcia

http://revistas.um.es/flamenco

Una vez estrenada Mater Lux, Jesús Arias continuó su faceta como compositor con un poema sinfónico sobre distintas ciudades que habían recibido bombardeos, Los cielos cabizbajos (Ordóñez y Collados, 2018), en el que estuvo trabajando hasta la noche anterior a su fallecimiento. La obra - estrenada en junio de 2018, con Jorge Rodríguez Morata como director y Estrella Morente, Lagartija Nick y David Montañés como intérpretes-— obtuvo un rotundo éxito. Tal y como sucedió con Rimado de ciudad u Omega, parte de una idea multidisciplinar y heterodoxa, en la que tienen cabida distintas músicas, sonidos y materias, logrando un todo integral, perfectamente unificado y completo.

\section{2.2 Faceta poética}

Desde pequeño, Jesús Arias se sintió atraído por las palabras y sus significados. Su padre, Antonio Arias, llevó a Jesús y a sus hermanos a Víznar para, tal y como el mismo Jesús haría años después con Joe Strummer, intentar averiguar en qué lugar se encontraba la tumba de Federico García Lorca (Molina, 2015). De este modo, la poesía de García Lorca se convertiría en un tema recurrente en su vida y en su producción artística y periodística (Barrio Canino, 2012). De ahí que Jesús Arias haga constante alusión a las obras de Lorca. Así, desde 1983, cuando compra la Antología Poética o Poeta en Nueva York, empieza a anotar diferentes poemas y versos para adaptarlos a sus letras, como puede comprobarse en Omega y en Eclipse, con poemas como "Omega" o "Niña ahogada en un pozo"; o con los versos sueltos "Cristo Moreno/Lirio de Judea y clavel de España" (Ochoa, 2012).

Además de la influencia de Lorca, la poesía y la literatura en general siempre llamó la atención de Arias; de hecho, en sus publicaciones periodísticas hace continuas referencias, entre otros, a Miguel Hernández, Francisco Ayala, Luis García Montero, Juan de Loxa o Antonio Muñoz Molina. En su etapa como estudiante universitario en Madrid, hablando una noche con Santiago Auserón ${ }^{3}$ llegaron ambos a la siguiente conclusión:

Aquel pop-rock incipiente de la "Movida madrileña" carecía de buenas letras. Fue, para mí, una noche de largo aprendizaje. Santiago, licenciado en filosofía por la Sorbona de París, me contaba que en inglés uno podía decir dos ideas con un solo verso, pero que en castellano necesitabas cuatro versos para explicar una idea. La conversación terminó derivando en García Lorca y en nuestra mutua pasión por escribir buenos versos. Yo le dije que para mí era más importante la letra de una canción que la música en sí. Los dos estuvimos de acuerdo. Creo que aquella misma noche, en su casa, me puso la primera maqueta de "El jardín botánico" (yo le replicaría con "El jardín extranjero" poco después) (Molina, 2015).

Es por este motivo por el que Jesús Arias pone especial interés en las letras de sus canciones. Pero, además de las letras de las canciones, Jesús Arias escribió también algunos poemas. Se desconoce el número total de ellos o sus temáticas, pues la mayoría no han llegado a publicarse. No obstante, cabe destacar uno de sus poemarios, titulado Un jardín contra tu nombre, recientemente publicado y editado por Isabel Daza (Arias y Daza, 2019).

\section{【 2.3 Faceta periodística}

La música y la poesía no fueron los únicos medios de expresión de Jesús Arias para exponer sus pensamientos y reflexiones. El artista granadino lo hizo también a través de la prensa, con la que estuvo ligado tanto de manera directa como indirecta.

\footnotetext{
${ }^{3}$ Santiago Auserón (1954) es un cantante, compositor y escritor, principalmente conocido por ser el compositor y vocalista del grupo Radio Futura (1979-1992).
} 
En efecto, a lo largo de su vida, Jesús Arias se desempeñó en diferentes trabajos relacionados con la prensa granadina (Redacción de La Vanguardia, 2016). Por un lado, fue el periodista local del Gabinete de prensa del Festival Internacional de Música y Danza entre 1992 y 1994, labor que desempeñó junto a Teresa del Río y el jefe de prensa Arturo Reverte, persona encargada de las noticias del ámbito nacional. Por otro lado, durante unos meses de 1994, una vez finalizada su colaboración con el Festival Internacional de Música y Danza, Arias se encargó de cubrir la información relativa a la Orquesta Ciudad de Granada. Por último, y tal vez más importante, colaboró cerca de treinta años con distintos periódicos de la geografía tanto local como nacional.

A la temprana edad de veintiún años, comenzó su andadura en el mundo periodístico. La mayoría de documentos existentes sobre la figura de Jesús Arias recogen el dato de que ejerció como periodista, pero sólo unos pocos informan acerca de dónde trabajó. Pero, en el caso de que se mencione dónde, casi siempre se cita únicamente los diarios El País y Granada Hoy cuando, en realidad, colaboró en muchos más. En efecto, desde que se iniciara en su labor periodística, en torno a 1984, además de los dos citados, escribió en otros periódicos, como Diario de Granada, El Día de Granada, Granada 2000, Diario 16 o El Independiente de Granada. Como puede comprobarse, la mayoría de ellos, a excepción, de El País y Diario 16, eran de ámbito provincial. En estos dos últimos, Arias desempeñó el papel de corresponsal de la ciudad de Granada, aunque en ocasiones puntuales debía atender su trabajo desde Sevilla.

$\mathrm{Su}$ faceta periodística le sirvió como complemento a su formación musical y poética. Al igual que solía hacer con la música, en reiteradas ocasiones interrelacionaba el periodismo con diferentes disciplinas: musical, arquitectónica, poética, cine, pictórica o escultórica, entre otras. Cerca de treinta años dentro del mundo periodístico y unas casi cinco mil publicaciones abalan esta formación holística.

Una vez descrita, siquiera sucintamente, la trayectoria artístico-profesional de Jesús Arias, ya es posible tomar conciencia de la herencia cultural que legó a la sociedad. La manera de Arias de entender el arte ha supuesto indudablemente un enriquecimiento de nuestra cultura, tanto a nivel musical, como poético y periodístico y no sólo circunscrito al granadino sino con repercusiones nacionales. Efectivamente, él fue uno de los introductores en Granada de un nuevo género musical, el punk. Concibió la música dentro de un abanico inmenso de posibilidades auditivas (no sólo ciñéndose al sonido puramente dicho, sino incluyendo ruidos, voces de momentos o personas en particular o sonidos de alarmas, entre otros elementos); fusionó la música comúnmente denominada "clásica" con géneros de música popular o experimental, tal y como podemos observar en Eclipse o Mater Lux (coro, voz flamenca, theremín y yunque); dada su capacidad para interrelacionar la música con otras manifestaciones artísticas como la poesía o la fotografía, dio a luz proyectos como Rimado de ciudad, Eclipse o el mismo planteamiento de Omega, al que nos referiremos a continuación. De ahí que consideremos a Jesús Arias como una de las figuras más importantes del panorama cultural granadino de las últimas décadas, que, potenciada por la personalidad de Enrique Morente, consiguió plasmar una de las ideas más complejas, completas y brillantes del panorama musical de los últimos tiempos, Omega.

\section{La participación de Arias en Omega}

Más de una década después de la fusión entre la poesía de Luis García Montero y la música de T.N.T. y Magic, cuyo resultado fue Rimado de ciudad, tuvo lugar una nueva fusión entre música y poesía. En 1996, sale al mercado Omega, disco del cantaor Enrique Morente y de la banda de punk-rock Lagartija Nick. Esta grabación se convierte en un referente dentro del panorama musical andaluz y nacional, aunque en principio no pareciese tener un futuro muy halagüeño (Barrera, 2014). Fusión entre el flamenco más tradicional y las músicas urbanas, es reconocido 
(C) Servicio de Publicaciones de la Universidad de Murcia

http://revistas.um.es/flamenco

por el sector más purista del flamenco (ibidem), obteniendo a su vez aceptación entre el público. Conviene advertir, no obstante, que el reconocimiento mayoritario llegó más tarde, con el paso de los años (Sáenz, 2012). Pero, ¿cuál es el origen de Omega?

Justo aquí, en el germen, es donde cobra importancia la figura de Jesús Arias, pues puede afirmarse que él fue, en primera instancia, el ideólogo de un proyecto con el que buscaba «un choque de trenes entre flamenco y punk-rock» (Manrique, 2012).

\section{3.1 Antecedentes}

En 1977, Jesús Arias (que en ese momento tenía catorce años) escucha por primera vez "Mírame a los ojos" del disco Despegando de Enrique Morente. Arias queda maravillado por la fuerza y coraje de la obra y, aunque tenía otras influencias musicales (en este momento escucha más música anglosajona que flamenco), esta pieza y este cantaor revoloteaban siempre en su pensamiento (Arias, 2016).

Casi trece años antes de la salida al mercado de Omega, en 1983, Jesús Arias descubre la Antología poética de Federico García Lorca, a la vez que los temas de The rhythm of he head de Peter Gabriel. De hecho, la idea básica del proyecto nace cuando Arias escucha la música de Peter Gabriel leyendo el poema "Omega" de la Antología poética lorquiana (Pérez, 2016). Es en este momento cuando Jesús Arias empieza a reflexionar sobre una posible fusión entre la poesía de García Lorca y una música con potencia y garra, tal y como le sugirió que la canción "Mírame a los ojos" de Enrique Morente (ibidem).

Hace entonces acto de aparición otra figura relevante del proyecto, Raúl Alcover $4^{4}$ que, pasado el tiempo, en 1995, sería quien pusiera a Jesús Arias en contacto con Enrique Morente.

Años antes, en 1987, Jesús Arias había realizado una reseña del disco de Raúl Alcover Del laberinto al treinta para el periódico Día de Granada, en la que valoraba de forma muy positiva dicha grabación y resaltaba la brillantez del músico y productor granadino (Arias, 1987; figura 5).

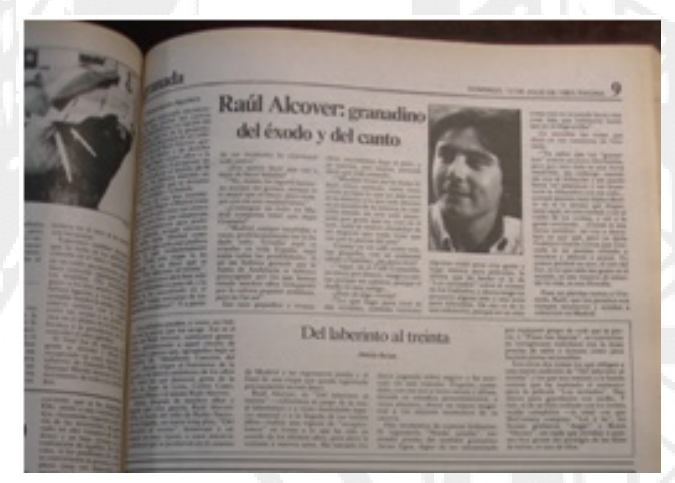

Figura 5. Reseña de Jesús Arias del disco de Raúl Alcover Del laberinto al treinta (Día de Granada, 12 de julio de 1987)

\footnotetext{
${ }^{4}$ Raúl Alcover es un músico, arreglista, compositor y productor granadino, nominado a los premios Goya y ganador del Premio de la Música en España.
} 
Revista de Investigación sobre Flamenco "La madrugá" n. ${ }^{\circ}$ 18, diciembre 2021, ISSN 1989-6042

\section{3.2 Proyecto Omega}

No será hasta 1995 cuando Jesús Arias exponga por primera vez de manera formal la idea que le ronda la cabeza, juntar música rock o punk con poemas de García Lorca (Arias, 2016). En reiteradas ocasiones, había intentado coincidir con Enrique Morente para plantearle el proyecto pero, justo hasta entonces, no surgió la ocasión. Esta se produjo con el entierro de Rafael Fernández Píñar (concejal de cultura), evento que reunió a un gran número de personalidades de la cultura granadina (Pérez, 2016). Entre los asistentes estaban Raúl Alcover (quien era mano derecha de Enrique Morente durante esos años) y el propio Jesús Arias. Ese día ambos entablaron conversación y terminaron hablando de la idea de este, que en los últimos tiempos había cogido más forma, ya que había pensado mezclar en una misma canción el poema "Omega" de García Lorca con el tema "Helter Skelter" de The Beatles (Arias, 2016). Alcover hizo de enlace, y Enrique Morente citó a Arias para que le explicase detalladamente su idea.

Jesús Arias le expuso la idea a Enrique Morente y le interpretó parte de lo que había preparado, cantando la letra del poema "Omega". A ese encuentro entre Jesús Arias y Enrique Morente -que por aquel entonces estaba buscando una banda de punk-rock para realizar un proyecto similar (Barrio Canino, 2012) - asistió también el hermano de Jesús, Antonio, líder de Lagartija Nick. Al cantaor granadino el planteamiento le pareció interesante y por ese motivo le pidió a Jesús Arias que hiciera un informe detallado sobre cómo lo concebía en su totalidad. Como señala Pérez (2016), de este informe salieron 113 folios de los que partiría la idea de Omega.

Una vez que Morente comprobó cómo tocaban Lagartija Nick y sopesó meditadamente el estudio redactado por Jesús Arias, aceptó la propuesta. Es en ese momento cuando nace Omega, título sugerido por el propio Arias (Pérez, 2016). He aquí una de las razones por las que Morente es un músico visionario que traspasa fronteras: sabe ver el arte más allá de los cánones estipulados de lo que "debería ser" el flamenco y entiende que la música es un elemento en constante cambio y transformación.

En la parte musical del informe, Arias propone una serie de indicaciones, de las que se extractan algunas a continuación:

Morente podría hacer canciones al más puro estilo flamenco. Esas canciones tendrían, como fondo, sin embargo ruido de guitarras eléctricas, muy bajas, apenas perceptibles pero presentes. O acompañamientos de ritmos de batería de Eric. Del mismo modo, en los temas individuales de Lagartija Nick aparecería la voz de Morente como trasfondo... ni Enrique Morente tiene por qué adaptar su voz a los cánones del rock, porque sería, simplemente, absurdo. El proyecto Omega debe ser una confluencia de estilos, de sensibilidades y de ritmos, no una fusión flamenco-rock. Se trata de crear. Y aquí se dan todas las posibilidades (Pérez 2016).

Jesús Arias sugería utilizar alarmas, estruendos o ruidos pero, respecto a eso, Enrique Morente se mostró escéptico, puesto que ya estaba revolucionando el flamenco realizando un disco con un grupo de rock (Tébar, 2012).

Una vez comenzaron los ensayos, el idea inicial de Omega de Jesús Arias tomó otros derroteros, puesto que, como señala Pérez (2016), fueron Enrique Morente y Lagartija Nick los que interpretaron e hicieron la grabación del disco. Pero, hay que insistir en ello, al fondo seguía estando la idea concebida por Jesús Arias. Él propio Arias (2006) describe, en un artículo para el periódico Granada Hoy, el proceso seguido que culminó con la grabación del álbum Omega y hace también referencia a una de las peculiaridades de su concepción del arte, en el que pone en interrelación diferentes formas de expresión como la música, la poesía y el periodismo (figura 6). 
(C) Servicio de Publicaciones de la Universidad de Murcia

http://revistas.um.es/flamenco

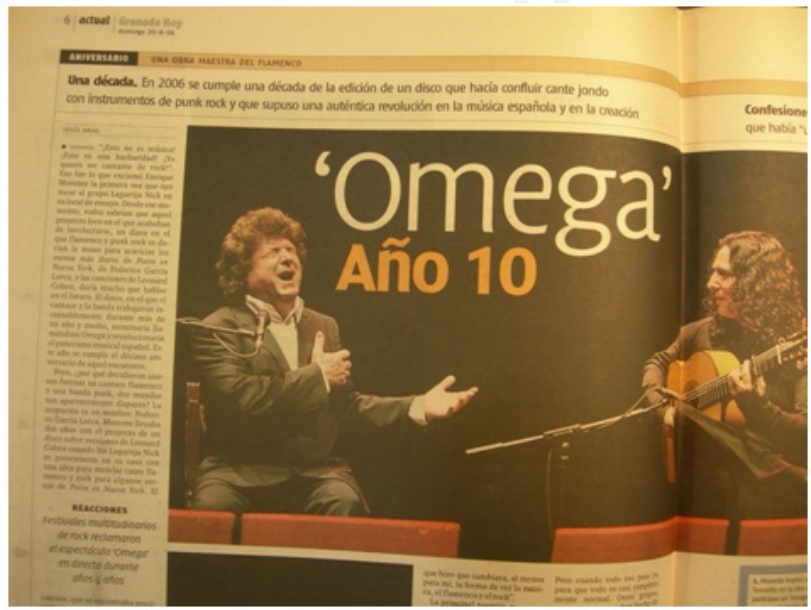

Figura 6. Artículo de Jesús Arias conmemorando el décimo aniversario de Omega (Granada Hoy, 20 de agosto de 2006)

\section{Jesús Arias y Enrique Morente: la conjunción de dos astros}

Ambos artistas coincidieron en la manera de enfocar el arte, desde un prisma multidisciplinar, complejo y heterodoxo, y esto, aun partiendo de puntos vitales y musicales totalmente distintos. Por una parte, Jesús Arias, llevaba años dándole vueltas a un proyecto con voz flamenca, agrupación de rock y con las letras de Lorca, partiendo de un punto de vista joven y rebelde ante lo socialmente establecido y con unas ideas musicales que querían romper esquemas. Por otra, Enrique Morente, un maestro consolidado del cante, admiraba fehacientemente a Lorca y, además, sentía curiosidad y atracción por otros géneros musicales.

De este modo, con su proyecto, Morente demostró su actitud flamenca de garra y fuerza de la que allá por 1977 Arias quedó prendado al escuchar "Mírame a los ojos" del disco Despegando, abierto y preparado para ahondar nuevos horizontes de la mano de músicos (los hermanos Arias) que en principio no pertenecían a su mundo musical y que simplemente le ofrecían hacer arte (se llamara flamenco, rock o punk).

Visionarios de un proyecto que superaba todo lo anterior dentro de la escena musical granadina, Morente y Arias, junto con Lagartija Nick y los demás participantes, crearon uno de los estandartes musicales más importantes que ha dado la ciudad de Granada, Omega.

Tras la muerte de Morente, Arias, que lo recordaba desde la amistad y desde la profunda admiración que le profesaba, se refirió a él en estos términos:

Es que Enrique Morente era absolutamente inmortal. El tío que más se reía del mundo, el que más bromeaba, el que más cosas te enseñaba con esa filosofía económica que tenía él, la filosofía de la ironía, de la broma con doble sentido, con triple sentido, de la ternura en los ojos, de esos ojos chiquitillos que te miraban con intensidad e inteligencia. Un tío con esa sabiduría no puede morirse nunca. Yo aún pienso que es una mentira, otra broma suya, que cualquier día, al doblar una esquina, me lo voy a volver a encontrar. Pero sé que me lo voy a encontrar porque está ahí, en lo que recuerdo de él (Ochoa, 2012). 
Revista de Investigación sobre Flamenco "La madrugá" n. ${ }^{\circ}$ 18, diciembre 2021, ISSN 1989-6042

\section{Bibliografía}

Arias, Jesús. (1987). Del laberinto al treinta. Día de Granada (12 de julio, p. 9).

Arias, Jesús. (2006). 'Omega' Año 10. Granada Hoy (20 de agosto, pp. 6-7).

ARIAS, Jesús (2016). La gestación y desarrollo de una obra maestra. Flores del Fango - Blogzine. Recuperado de https://cutt.ly/8TBxOrX.

ARIAS, Jesús y DAZA, Isabel (2019). Un jardín contra tu nombre. Granada: Patronato Cultural Federico García Lorca - Diputación de Granada.

Barrera Ramírez, Fernando. (2014). Hibridación, globalización y tecnología: Flamenco y música indie en Andalucía (1977-2012) (tesis doctoral). Granada: Universidad de Granada, Departamento de Historia y Ciencias de la Música. Recuperado de https://hera.ugr.es/tesisugr/24145518.pdf.

BARrio CANino (2012). Entrevista a Quäsar. Recuperado de https://cutt.ly/KTBxQMF.

Cono Canticum Novum (2014). Cantata Mater Lux. Jesús Arias. Notas sobre la obra. Recuperado de https://cutt.ly/ETBxJFa.

Iglesias Castro, Brais (2015). Jesús Arias: "Joe Strummer no sólo marcó una época musicalmente. Creó una actitud". Recuperado de https://cutt.ly/WTBxROf.

MANRiQue, Diego (2012). La visión cósmica de Qüasar. El proyecto de Jesús Arias desarrolla el concepto original de "Omega", el rompedor disco de Enrique Morente El País (17 de marzo). Recuperado de https://cutt.ly/MTBxXJA.

Molina, Juanfran (2015). Jesús Arias: "el creador contra los elementos". Música para Psicocamaleones. Recuperado de https://cutt.ly/QTBxBCK.

Musikaze (2010). T.N.T., componentes: Jesús Arias. Recuperado de https://cutt.ly/TTBxDIu.

OchoA, Arturo (2012). "Eclipse", una catedral musical para Granada. Diagonal (23 de marzo). Recuperado de https://cutt.ly/4TBxllX.

Ordóñez Eslava, Pedro y Collados Alcaide, Antonio (Eds.) (2018). Jesús Arias: Diario(s) de artista: Omega, Mater Lux y Los cielos cabizbajos. Granada: Editorial Universidad de Granada.

Pereira, Silvia (2017). "Cuando seamos mayores vamos a ser artistas", afirmaba rotundo Jesús Arias con siete años. Diario digital Chana Press. Recuperado de https://cutt.ly/DTBx2cn.

PÉREz, Juan Ignacio. (2016). El "Omega" de Jesús Arias (I). El Independiente de Granada. Recuperado de https://cutt.ly/aTBx7RY.

Redacción de La VANGUARdia (2016). Acto con Lapido y Antonio Arias homenajeará a músico y periodista Jesús Arias. La Vanguardia (24 de febrero). Recuperado de https://cutt.ly/5TBxq4Q.

RodríGuez, Pablo. (2015). Mater creciente, mater menguante. Ideal (14 de abril). Recuperado de https://cutt.ly/vTBcqYX.

SÁenz, Consol (2012). Músiques clandestines - 5 de maig. Recuperado de https://cutt.ly/JTBxvKY.

TÉBAR, Eduardo (2010) June 16). El punk sempiterno de T.N.T. (Real Media file, 16 de junio). Recuperado de https://cutt.ly/yTBxpb8.

TÉBAR, Eduardo (2012). Jesús Arias, sobreviendo al punk. (Real Media file, 23 de febrero). Recuperado de https://cutt.ly/QTBxfUq. 